University of Nebraska - Lincoln

DigitalCommons@University of Nebraska - Lincoln

Faculty Publications, Department of Psychology

Psychology, Department of

April 1999

\title{
Child Physical Abuse and Neglect
}

Jody E. Warner-Rogers

MRC Child Psychiatry Unit, de Crespigny Park, Denmark Hill, London SE5 8AF United Kingdom

David J. Hansen

Univertsity of Nebraska-Lincoln, dhansen1@unl.edu

Debra B. Hecht

University of Nebraska-Lincoln

Follow this and additional works at: https://digitalcommons.unl.edu/psychfacpub

Part of the Psychiatry and Psychology Commons

Warner-Rogers, Jody E.; Hansen, David J.; and Hecht, Debra B., "Child Physical Abuse and Neglect" (1999). Faculty Publications, Department of Psychology. 219.

https://digitalcommons.unl.edu/psychfacpub/219

This Article is brought to you for free and open access by the Psychology, Department of at DigitalCommons@University of Nebraska - Lincoln. It has been accepted for inclusion in Faculty Publications, Department of Psychology by an authorized administrator of DigitalCommons@University of Nebraska - Lincoln. 
Published (as Chapter 16) in Handbook of Psychological Approaches with Violent Offenders: Contemporary Strategies and Issues, edited by Vincent B. Van Hasselt and Michel Hersen. Kluwer Academic/Plenum Publishers, New York, 1999. Pages 329-356. Copyright (C) 1999 Kluwer Academic/Plenum Publishers/Springer Verlag. Used by permission.

\title{
Child Physical Abuse and Neglect
}

\author{
Jody E. Warner-Rogers \\ MRC Child Psychiatry Unit, de Crespigny Park, Denmark Hill, London SE5 8AF United Kingdom \\ David J. Hansen and Debra B. Hecht \\ Department of Psychology, University of Nebraska-Lincoln, Lincoln, Nebraska 68588-0308
}

\section{Introduction}

Children ideally develop and learn about their world from the safe and stimulating environment of their home. Therefore, it is quite disturbing when violence occurs within the supposedly protective domains of the home and the parent-child relationship, although such acts have been committed throughout history (Zigler \& Hall, 1989). Even though acts of child maltreatment have a long history, the concept that society should be responsible for the protection of children, including identification, reporting, and treatment of both the victims and perpetrators of maltreatment, is a relatively recent development.

This chapter addresses the physical abuse and neglect of children by their parents. The problems of child physical abuse and neglect are described, including historical and epidemiological information and the characteristics of maltreating parents and families. A discussion of assessment methods as they apply to case conceptualization and treatment is provided. The basis for any well-planned treatment lies in a thorough assessment, and this is particularly true for the complex problem of child maltreatment. Interventions to address the needs of abusive and neglectful parents and prevent the recurrence of maltreatment are also described. In addition, issues in the clinical management of the problems and treatment of these challenging families are discussed.

\section{Description of the Problem}

Physical abuse can be defined as an act of "commission," in which physically aggressive behavior on the part of a caretaker is directed toward a child and results in injury or harm to that child (Kelly, 1983b; National Center on Child Abuse and Neglect [NCCAN], 1988). Neglect can take many forms, but has been defined globally as an act of "omission," in which caretakers fail to provide for a child's basic physical, medical, edu- 
cational, or emotional needs (Kelly, 1983b; NCCAN, 1988). Physical abuse involves discrete incidents of violence directed toward a child. In contrast, neglect is characterized by more chronic patterns of substandard care in which a parent fails to meet the child's basic needs (Kelly, 1983b; Wolfe, 1988). Direct observation of physically abusive or neglectful behavior is uncommon, since it occurs in the relative privacy of the home environment. As a result, identification of both physical abuse and neglect is often based on the consequences of maltreatment rather than observation of actual maltreating behavior (Hansen \& Warner, 1994). The immediate consequences of physical abuse (i.e., physical trauma) may be more easily identified compared with the consequences of neglect, which may have neither an immediate nor obvious effect on children's health and development. Although neglect does not involve violent behavior, and the causes of neglect may differ from those involved in physical abuse, the two forms of maltreatment often co-occur (Hansen, Warner-Rogers, \& Hecht, 1998).

Throughout their early years, children must learn to negotiate certain central and specific developmental tasks, such as acquiring communication and social skills and learning to regulate their behavior and affect in response to the environment. Maltreatment has been conceptualized as a failure of the environment to provide a child with opportunities for normal development and the acquisition of such knowledge and skills (Cicchetti \& Lynch, 1995). Maltreatment undoubtedly presents a serious impediment to a child's behavioral, social, and academic development. In addition to the possibility of physical injury or health problems as a result of maltreatment, physically abused and neglected children have been shown to have delays in language acquisition, deficits in intellectual and academic functioning, aggression and peer problems, and emotional problems such as hopelessness, depression, and low self-worth (see Ammerman, Cassisi, Hersen, \& Van Hasselt, 1986; Azar \& Wolfe, 1989; Hansen, Conaway, \& Christopher, 1990; Malinosky-Rummell \& Hansen, 1993). In the most severe cases, the consequences of maltreatment can be fatal-more than 1,000 children die from physical abuse and neglect each year (NCCAN, 1988, 1996).

Abusive and neglectful families tend not to report themselves for treatment; less than $1 \%$ of reports to statewide protection agencies are made by the perpetrators (NCCAN, 1994). This has important implications for treatment, as abusive families may not view themselves as having any problems or difficulties in need of intervention. Thus, identification and reporting of physically abusive and neglectful families by professionals is often the first step in the treatment process (Warner \& Hansen, 1994). In fact, all states have mandated reporting laws through which physicians, psychologists, teachers, and other professionals are required to report suspected instances of child maltreatment. Despite such laws, research suggests that as many as one third of possible child physical abuse cases remain unidentified or unreported (e.g., NCCAN, 1988, 1996).

\section{Historical Background}

Throughout history, children have often been treated with incredible cruelty, including abandonment, domination, beatings, murder, forced labor, and imprisonment (Zigler \& Hall, 1989). The historical context of child abuse can be useful for understanding its senselessness and brutality. For example, infanticide during some points of history in 
some cultures occurred as a population control measure to help the community survive (Zigler \& Hall, 1989). Other abuse events have no such contextual factors and appear only senseless and extreme. Although there is evidence in recent decades that child abuse is increasing, Zigler and Hall point out that if one takes a historical view, there has been much improvement in how children have been treated over the ages. Evidence of the abuse of children is as old as recorded history, but the study of child abuse has relatively recent beginnings. Widespread societal concern over child abuse as a significant problem dates back only to the 1950s and 1960s (Hansen et al., 1990; Wolfe, 1988).

"Why does a parent physically abuse his or her child?" is a question professionals have been trying to answer for well over 30 years (Spinetta \& Rigler, 1972, p. 296). The medical community was among the first group of professionals to question how and why certain types of childhood injuries could be obtained " accidentally." This line of questioning culminated in the seminal paper by Kempe, Silverman, Steele, Droegemuller, and Silver (1962), which described the "battered child syndrome" and formed the foundations on which theories of assessment and intervention for physically abusive parents were based for many subsequent years.

Initially, a categorical approach was used to conceptualize physically abusive behavior, in part because the initial focus was on very severe maltreatment. Such aggressive and hostile behavior directed toward a child was viewed as a distinct deviation from "normal" parenting behavior and, as such, was thought to be due to severe psychopathology in the parent (Kempe et al., 1962; Steele \& Pollack, 1974). The cause of maltreatment was considered unidimensional and direct: psychiatrically disturbed parents abused children.

However, within a few years of the identification of the "battered child syndrome," research showed that the majority of abusive parents were not psychotic and the majority of maltreatment did not result in severe, life-threatening injuries but rather moderate or mild injuries (Kempe \& Helfer, 1972; Spinetta \& Rigler, 1972). The field broadened from the narrow focus on psychiatric illness of offenders to the more general aspects of parental functioning and the context in which parenting occurs (Belsky \& Vondra, 1989). Efforts were made to determine the characteristics of those most at risk for maltreating their children and to identify the situations in which abuse was most likely to occur.

A dimensional approach, which places abusive behavior on a general continuum of parenting practices, evolved to replace the categorical model (Azar \& Wolfe, 1989; Hansen et al., 1990; Wolfe, 1988). Those parenting practices considered most unsuitable and harmful to a child are at the negative end of the continuum, while those actions that facilitate social, emotional, and cognitive development comprise the positive end (Azar \& Wolfe, 1989), Similarly, disciplinary strategies such as attending to and rewarding prosocial behavior fall at the positive end while harsh, aggressive physical discipline is found at the negative end.

\section{Epidemiology}

The Third National Incidence Study of Child Abuse and Neglect (NIS-3), the most comprehensive study of the incidence of child abuse and neglect in the United States, was recently reported by the National Center on Child Abuse and Neglect (NCCAN, 
1996). The NIS-3 data were collected during 1993 from a nationally representative sample of more than 5,600 professionals from 842 agencies in 42 counties. Abuse and neglect were defined according to two standards: (a) the harm standard, in which children were considered maltreated if they had already experienced harm (i.e., physical, emotional, or behavioral injury); and (b) the endangerment standard, a more inclusive standard in which children were considered maltreated if they experienced maltreatment that put them at risk of harm or if they had already experienced harm.

Overall, there were significant increases in the incidence of physical abuse and neglect since the previous National Incidence Studies (NCCAN, 1988, 1996). Based on the harm standard, it was estimated that 5.7 children per 1,000 were physically abused, with an estimated total of 381,700 children nationwide. This is a substantial increase from the earlier studies; the NIS-2 in 1986 was 4.3 children per 1,000 and the NIS-1 in 1980 was 3.1 children per 1,000. Based on the endangerment standard, it was estimated that 9.1 children per 1,000 were physically abused, with an estimated total 1.1 of 614,100 nationwide. This is also a significant increase over the NIS-2 estimates of 4.9 per 1,000. (Endangerment definitions were not used in NIS-1.)

The incidence of neglect is substantially higher than physical abuse. Based on the harm standard, it was estimated that 13.1 children per 1,000 were neglected, with an estimated total of 879,000 children nationwide. This is a significant increase from the earlier studies; the NIS-2 was 7.5 children per 1,000 and the NIS-1 was 4.9 children per 1,000. Harm standard rates across types of neglect were as follows: physical neglect, 5.0 per 1,000; emotional neglect, 3.2 per 1,000; and educational neglect, 5.9 per 1,000. Based on the endangerment standard, it was estimated that 29.2 children per 1,000 were neglected, with an estimated total of 1,961,300 nationwide. This is also a significant increase over the NIS-2 estimates of 14.6 per 1,000. Endangerment standard rates across types of neglect were as follows: physical neglect, 19.9 per 1,000; emotional neglect, 8.7 per 1,000; and educational neglect, 5.9 per 1,000 .

A variety of possible demographic correlates of physical abuse and neglect were examined in the NIS-3. Rates of physical abuse and neglect did not differ for male and female children. The only significant difference found in age for physical abuse was that the incidence of abuse among 12- to 14-year-old youth was more than double the incidence for those 0 to 2 years of age. For neglect the only age difference found was for emotional neglect, where the incidence for children ages 6 and older was six times higher than the incidence for children ages 5 and younger. There were no significant race differences for physical abuse or neglect.

The incidence of physical abuse in low-income families (less than $\$ 15,000$ family income per year) was more than twice the rate in middle-income families $(\$ 15,000$ to $\$ 29,999$ per year) and sixteen times the rate for children in high-income families (more than $\$ 30,000$ per year). Patterns of neglect showed similar differences. fu addition, the abuse experienced by children of lower income families tends to be more severe than that experienced by children from higher income families. These families may be more likely to reside in impoverished communities where resources are scarce.

Physical abuse was significantly more common in father-only households than with two-parent families, whereas rates for single-mother households were not different from two-parent families. Neglect was significantly higher among children with a single parent, father or mother, than two-parent families. Physical abuse rates did not differ across family size, whereas neglect was most likely in larger families (i.e., with four or more chil- 
dren). Metropolitan status of the community (i.e., very large urban, moderate urban, suburban, and rural) was not related to the incidence of physical abuse or neglect.

The NIS-3 estimated that approximately 1,500 children a year died from maltreatment, with $80 \%$ of those deaths being caused by natural parents. Approximately $78 \%$ of fatalities were due to a female parent or parent substitute. Serious injury (i.e., involving a life-threatening condition, representing a long-term impact, or requiring professional treatment to prevent long-term impairment) occurred in approximately 565,000 children nationwide, with $87 \%$ caused by natural parents.

Most physical abuse (71 \%) was committed by natural parents, with $21 \%$ being other parents (e.g., step or foster) or parent substitutes, and the remainder being committed by others (e.g., other family members or unrelated adults). Most neglect was by natural parents $(91 \%)$, with other parents or parent substitutes responsible for $9 \%$.

\section{Characteristics of the Offender}

A host of factors can impact parenting and these factors can be associated with the parents themselves, their child, the relationships in the family, and the broader context in which parenting occurs. Physical abuse is most likely to occur when parents are attempting to discipline their child or otherwise manage the behavior of their child (Wolfe, 1988). Certain situational factors may have a direct, immediate influence on maltreatment by escalating the intensity of these parent-child interactions. Other factors may contribute to maltreatment more indirectly by compromising the overall quality of parenting or the home environment. Poor child management skills, stress, knowledge deficits, motivational and anger control problems have all been identified as factors that can compromise parenting (Hansen et al., 1990; Hansen \& Warner, 1992). Parental psychopathology, such as depression, can strain parental resources and thus interfere with the ability to provide an optimal home environment (Quamma \& Greenberg, 1994). Furthermore, marital discord has been shown to have a negative impact on parenting skills and the availability of the parents (Kerig, 1995). Certain models of maltreatment focus on the etiology and maintenance of abusive behavior by attempting to account for how and why parents move along the continuum from milder to more harmful interactions with their child. For example, Wolfe (Azar \& Wolfe, 1989; Wolfe, 1987) described a three-stage transitional model. Stage 1 is characterized by a reduced tolerance to stress and disinhibition of aggression in the parent. Stage 2 is associated with poor handling of acute crises, precipitated by the parent's early, failed attempts at controlling stress and misbehavior that lead to more power-assertive, punitive methods. Stage 3 consists of the habitual, coercive patterns of aggression and arousal in which excessive punishment functions to decrease child misbehavior. At each stage, compensatory factors (e.g., supportive spouse, social support) may decrease negative interactions, whereas destabilizing factors (e.g., stressful life event, increase in child behavior problems) may increase negative interactions and thus heighten the risk for abuse.

An interactive model of child abuse views parenting as occurring in the context of other behavioral, biological, affective, cognitive, and societal variables. This provides a useful and contemporary conceptualization of physically abusive behavior. One such model, provided by Walker, Bonner, and Kaufman (1988), involves the following four te- 
nets: (a) certain parental factors (e.g., personality characteristics) predispose individuals toward abusive behavior, (b) these factors can lead parents to have a disturbed relationship with their child (e.g., unrealistic expectations, inconsistent child management strategies), (c) certain factors associated with the child may render their behavior more difficult to manage (e.g., high rates of challenging behaviors), and (d) sociological issues (e.g., low income) can contribute to a negative environment in which abuse is more likely to occur. In summary, physical abuse and neglect can be viewed as a multifaceted problem that results from complex maladaptive interactions between parents and children, combined with a lack of essential caregiving behaviors.

Appropriate parenting that is characterized by predictability, responsiveness, and sensitivity, and is provided within a structured and organized home environment, has long been recognized as crucial for optimal child development (Maccoby \& Martin, 1983). The ability to provide such parenting is multidetermined (Belsky \& Vondra, 1989); the inability to provide such parenting is also multidetermined. It is not surprising, therefore, that there is no adequately validated "typical perpetrator profile" of a maltreating parent (Milner \& Chilamkurti, 1991). Rather, it is more useful to view maltreatment in the context of a continuum of parenting and to examine the factors that compromise the quality of parenting and thus increase the risk of abuse and neglect.

Research suggests areas of parenting behaviors that may differentiate abusive from nonabusive parents, including child-management techniques, anger and impulse control, and parent-child interactions (Azar \& Wolfe, 1989; Walker et al., 1988; Wolfe, 1988). For example, when observed in play or other interactive situations with their children, abusive mothers tend to interact less often with their children than do nonabusive mothers (e.g., Schindler \& Arkowitz, 1986). The interactions that do occur tend to be more negative and less supportive (e.g., Bousha \& Twentyman, 1984). Abusive mothers have been found to engage in less positive nonverbal and verbal behavior and more verbal and nonverbal aggression (e.g., Reid, Kavanagh, \& Baldwin, 1987). Abusive mothers also tend to use more power-assertive child-management strategies (e.g., disapproval, humiliation, threat) and less positive techniques (e.g., approval, cooperation, reasoning), and to issue more commands compared with nonabusive counterparts (e.g., Oldershaw, Walters, \& Hall, 1989). Overall, abusive mothers have been noted to view their children less favorably than nonabusive mothers view their children (e.g., Oldershaw et al., 1989). Like many issues in maltreatment, the majority of research has been on abusive mothers. Much less is known about the qualitative aspects of interactions between abusive fathers and their children.

Parents need to be sensitive to their child's changing needs at different stages of development. They also need to be attentive to and perceptive of the cues provided by their child's behavior and learn to respond to those cues appropriately. Abusive parents tend to lack accurate knowledge about child rearing and have unrealistic expectations for their children's behavior (e.g., Azar, Robinson, Hekimian, \& Twentyman, 1984; Spinetta \& Rigler, 1972). They may have a tendency to view their child's behavior in a negative manner, and describe their children as purposefully disruptive, noncompliant, and annoying (e.g., Bauer \& Twentyman, 1985). Abusive parents may also view misbehavior differently from nonabusive parents and therefore may not be reliable reporters of their own child's behavior. For example, though they may describe their child as ex- 
hibiting more behavioral difficulties than other children, independent observation may fail to detect such differences (Reid et al., 1987).

General life stressors appear more pronounced in maltreating families. Chaotic lifestyles, characterized by problems such as marital discord and frequent moves are often evident (Azar \& Wolfe, 1989; Lundquist \& Hansen, 1998). Physical health issues may be present, as abusive parents tend to report more health problems than would be expected in the general population (Milner, 1986). Overall psychological health can impact coping and parenting. High rates of depression have been linked to maltreatment, with physically abusive mothers in particular reporting more physical symptoms (Lahey, Conger, Atkeson, \& Treiber, 1984). The higher number and increased intensity of stressors faced by parents may place an unrealistic demand on coping skills already compromised by a weak preparation for the parenting role, increasing the likelihood that a parent will react to situations with aggressive behavior (Milner \& Chilamkurti, 1991).

Coping with stressors requires identifying the cause of the stress, generating and implementing a plan to reduce the stress, and attempting to prevent the stress from occurring or increasing in the future. All of these skills require some degree of insight, planning, and organization. Inability to solve problems related to parenting and other aspects of daily living is hypothesized to result in frustration or inability to cope and lead to problematic parental behavior such as physical abuse or neglect (Hansen, Pallotta, Christopher, Conaway, \& Lundquist, 1995). General coping and problem-solving skills are widely acknowledged to be underdeveloped in abusive parents and this observation has received some empirical support (e.g., Azar et al., 1984; Hansen et al., 1995; Hansen, Pallotta, Tishelman, Conaway, \& MacMillan, 1989). Limited problem-solving skills for childmanagement situations may result in a tendency to use verbal and physical aggression as conflict-resolution techniques. As noted earlier, compared with nonabusive mothers, abusive mothers tend to rely on more power-assertive, negative child-management strategies, such as hitting and pushing (Lahey et al., 1984; Oldershaw et al., 1989), and verbal reprimands and response cost punishment (Trickett \& Susman, 1988) when attempting to manage child behavior.

Although low intelligence has been identified in the literature as a possible risk factor for abuse (Kaufman \& Zigler, 1989; Schilling, Schinke, Blythe, \& Barth, 1982), support for this conclusion is debatable (Dowdney \& Skuse, 1993). Rather than focus on general intellectual ability, research suggests that the emphasis should be placed on specific problem-solving skills, including abstract reasoning and the ability to generate appropriate child-management strategies (Azar et al., 1984; Hansen et al., 1989; Hansen et al., 1995).

Anger can be seen as a natural occurrence of parenting. All children become difficult and oppositional at times, especially during certain developmental periods, and parental anger can be a natural and expected response to some child behavior (Hecht, Hansen, \& Chandler, 1996). In certain cases, however, anger may be an inherent part of a parent's style or can arise as a result of the incongruence between their expectations and the reality of parenting (Hecht et al., 1996). Abusive parents may have increased sensitivity to anger- or stress-inducing cues. For example, research has found abusive mothers to be more physiologically aroused by and averse to infant cries (Frodi \& Lamb, 1980) and to have greater and longer arousal to stressful stimuli (Wolfe, Fairbank, Kelly, \& Bradlyn, 1983). Maltreating parents may not recognize the physiological and cognitive cues 
of anger arousal or they may be less able to reduce their arousal level. Poor coping strategies and a lack of anger-management techniques may increase the likelihood that abusive parents will react in a hostile or angry manner. Poor impulse control may exacerbate the problems even further.

Social cognition is an important component in the conceptualization of parental anger. Milner (1993) proposed that maltreating parents have preexisting cognitive schemas, which include beliefs and values that impact the way they perceive, evaluate, integrate, and act on child-specific information. In the first stage of Milner's Social Information Processing Model, misperceptions of child behavior occur when parents focus on only part of the situation. This selective attention may be a result of predispositions or existing schemas, or could be due to the increased arousal and distress that maltreating parents report with respect to child behavior. The next stage involves the parents' interpretations and evaluations of the child's behavior. In particular, parental attributions of hostile intent by the child may contribute to aggression. Third, parents use the information they have obtained to choose a response, and parents may be poor observers and interpreters of anger cues. Alternatively, they may ignore the cues in order to maintain their preferred power-assertive behaviors.

Substance abuse may contribute to the problems of maltreatment. Estimates of the association between alcohol use and child maltreatment vary, probably due to the various definitions and samples used. Several studies in the 1970s found that approximately $50 \%$ of all child-abusing parents drank heavily or were intoxicated at the time abuse occurred (Orme \& Rimmer, 1981). Other reviews of the literature suggest that alcohol use was involved in $40 \%-95 \%$ of marital violence cases and in $32 \%-62 \%$ of child abuse cases (Coleman \& Straus, 1983). Studies have shown similar environmental and personality characteristics in alcohol abusers and child abusers (Milner \& Chilamkurti, 1991; Vaillant, 1995), including low levels of social support and self-esteem, high levels of stress and marital discord, and poor impulse control (e.g., Bavolek \& Henderson, 1990; Muller, Fitzgerald, Sullivan, \& Zucker, 1994).

Although child maltreatment and alcoholism may share similar etiologies and co-occur frequently, there is little convincing evidence that one phenomenon leads to the other (Orme \& Rimmer, 1981). Milner and Chilamkurti (1991) are hesitant to establish a causal link between alcohol use and maltreatment, especially given the lack of adequate controls and clear definitions in the literature. Rather, they suggest that alcohol may mediate cognition, and maltreating parents who drink might have their attention narrowed so that they concentrate only on the most immediate stimuli. Furthermore, abusers tend to make faulty attributions about child behavior. This processing style taken together with a diminished cognitive ability might lead to a violent response. Alternative hypotheses suggest that if maltreating parents are more easily aroused, they may drink to decrease this arousal (Stasiewicz \& Lisman, 1989).

The nature and quality of social contacts and social support also have important implications for child maltreatment. There is a link between elevated scores on the Child Abuse Potential Inventory on social isolation and the parent's perception of lack of support (Milner, 1994). The marital relationship, extended family, neighborhood network, and community outreach services can all be potential sources of support. These sources can have many positive functions such as educating parents about child rearing, modeling appropriate child-management techniques, giving or loaning money when necessary, or providing respite childcare. Supportive relationships can also provide outlets for 
talking through stressful situations or validating one's feelings about an issue. However, not all social networks support optimal parenting. Social networks can serve a negative function if maltreating parents select a peer group with similar problems who also exhibit maladaptive child-rearing strategies. Wahler (1980) was one of the first researchers to draw empirical attention to the issue that abusive mothers tend to have fewer social contacts than nonabusive mothers. Furthermore, the contacts they do have tend to be negative, rather than positive, and to involve professionals or relatives rather than friends.

Factors associated with the child, including gender, age, ordinal position, temperament, and behavioral characteristics, can influence parenting (Belsky \& Vondra, 1989; Maccoby \& Martin, 1983) and therefore can be possible risk factors for abuse. For example, with regard to physical abuse, there is some evidence that a gender effect emerges in later childhood with males under the age of 12 years and females over the age of 13 at most risk (NCCAN, 1994). In addition, children with developmental disabilities, especially those with oppositional or disruptive behaviors, are at increased risk for maltreatment (Ammerman, Hersen, Van Hasselt, Lubetsky, \& Sieck, 1994).

Abusive parents report more behavior problems in their children, focusing on negative, noncompliant behavior and ignoring the more positive, prosocial behaviors (Bousha \& Twentyman, 1984). When high levels of behavioral difficulties are paired with parenting skills already compromised by the presence of other risk factors, the potential for maltreatment may increase. Furthermore, because abusive parents may engage in less effective child-management strategies overall, they may actually exacerbate existing behavioral difficulties in their children by selectively attending to inappropriate or aggressive behavior, thus increasing the likelihood that these behaviors will occur more frequently. Although occurrence of abuse and neglect can co-vary with child behavior problems, it is important not to place any responsibility on the child for the occurrence of maltreatment (Hansen et al., 1990).

\section{Family Patterns}

Many family characteristics may not necessarily be targets for intervention, yet they are relevant for treatment planning through their association with increased risk for maltreatment or potential impact on treatment adherence (e.g., low socioeconomic status, marital or relationship problems). These factors may interact in a complex manner. For example, limited financial resources may place additional stress on a fragile marital relationship. Friction between caregivers may, in turn, exacerbate an already low tolerance for child misbehavior and trigger an angry, aggressive response to a rather minor incident of child noncompliance. Residing in a rural community may impact access to resources in general and increase likelihood of social isolation. In some communities, external supports may be available, but families most in need may not be able to access the support or may choose not to utilize it.

There is a long-standing belief that a childhood history of abuse significantly increases the likelihood of being an abusive parent and there is considerable evidence to support this link (Falshaw, Browne, \& Hollin, 1996; Kaufman \& Zigler, 1989; Widom, 1989). However, there are also problems with the research in the area, such as correlational and retrospective designs, and small, nonrepresentative samples (Falshaw et al., 1996; Spinetta \& Rigler, 1972; Widom, 1989). Despite the research difficulties and limitations, there appears to be 
a relationship between the seriousness and chronicity of childhood abuse and measures of adult child abuse, as well as associations between the observation of abuse in childhood and the potential to engage in abusive behaviors in adulthood (e.g., Milner, Robertson, \& Rogers, 1990). Even those adults who experienced less severe corporal punishment may be at increased risk for physically abusing their children (e.g., Straus \& Kantor, 1994).

The exact processes through which experiencing childhood maltreatment exerts its influence across generations are not known. There has been debate about the specificity of the effects of abuse-whether a specific form of abuse (e.g., physical abuse) is most likely to result in the intergenerational transmission of the same form of abuse (Falshaw et al., 1996). At the minimum, one can conclude that a history of abuse is a risk factor for offending behavior and that a childhood characterized by maltreatment provides weak preparation and poor modeling for the role of parenting in adulthood. A sociological view suggests that if parents and children share an environment and culture in which abusive behavior is frequent and acceptable, then the continuance of abuse is likely (Kaufman \& Zigler, 1989). Similarly, social-learning theory suggests that by witnessing and experiencing maltreatment, children are experiencing conditioned patterns of arousal, learning that it is appropriate, and forming rules and cognitive distortions around these beliefs (Kaufman \& Zigler, 1989; Widom, 1989). Attachment theory would suggest that internalized representations of past relationships serve as templates that dictate future relationships and that abusive patterns of interaction are integrated into these models (Kaufman \& Zigler, 1989).

Maltreatment in the home may not be the only violence children experience. Children who live in violent communities may be exposed to unpredictable violence directly (as victims of violence) or indirectly (as witnesses of violent acts). In such communities, the use of violence may be modeled repeatedly and even accepted as a solution to difficult situations. Exposure to increased crime and violence in the day-to-day community life may add yet more stress to parenting skills already taxed by limited personal resources. Cicchetti and Lynch (1995) present an ecological-transactional view to conceptualize the manner in which the effects of violence in the community interact with violence in the home to exert a negative influence on child development. The manner in which parents cope specifically with violence in their community may be influenced by levels of education, financial resources, and involvement with a support network such as church groups (Hill, Hawkins, Raposo, \& Carr, 1995).

\section{Assessment and Diagnosis}

If maltreatment is viewed in the context of parenting, then the focus of assessment must be based on the variables, such as those just discussed, that are known to impact parenting. In some cases, the most urgent and immediate goal of assessment may be to determine dangerousness and risk to the child; in other cases, the goal of assessment may be to determine whether abuse has occurred (Wolfe, 1988). However, if the family has been referred from social services or a child protection agency, the immediate decision about whether abuse occurred or whether to remove the child from the environment already may be resolved.

If that is the case, then the purpose of the assessment is more likely to involve the recognition of needs, the conceptualization of the problems, and the identification of 
targets for intervention. Thus, the initial step in the assessment process is to examine the basic skills and background that parents bring with them to the parenting role and to evaluate the context in which parenting occurs. The skills and background of parents includes their own childhood history of discipline, their knowledge of child development, problems with anger or impulse control, characteristics of the parent-child relationship, level of behavior problems exhibited by the child, and investigation of the child-management strategies currently used. Assessment should identify areas of strength and weakness in parenting and highlight possible risk factors. Evaluation of the parenting context involves consideration of the home environment, social support, and community resources. The assessment process also requires an in-depth, functional analysis of discrete episodes of maltreatment or times in which the parent found his or her skills particularly challenged. Antecedents that precipitate abuse should be identified (e.g., child misbehavior, spousal conflict, parental anger over a nonrelated issue), and consequences of abuse should be explored (e.g., child stops misbehaving, parent experiences release of stress).

Ideally, assessment is highly individualized, as every family will differ in terms of their strengths and vulnerabilities. A multimethod, multi-informant approach to assessment will yield the most valid and useful data and clinicians should view the information gathered via each separate method in conjunction with data from the other sources. Some techniques are most useful for the initial assessment to aid in problem identification and conceptualization. Other techniques can be incorporated into an ongoing assessment that is integral for documenting behavior change and monitoring progress throughout treatment. More extensive reviews of assessment measures and issues are available for interested readers (e.g., Hansen \& Warner, 1992; Milner, 1991).

\section{Clinical Interview}

Interviewing is an essential tool for gathering background information, assessing risk, and identifying antecedents and consequences of maltreatment. Data on parental knowledge regarding general child development and behavior can be collected via interview as well. Specific information on how parents view their own child and how they respond to problematic behavior is also easily gathered in this manner. Anger control issues can be raised in the neutral context of the interview. Similarly, topics such as quality of relationships and possibility of substance abuse can be addressed. Details as to availability and use of social supports can be gathered. Such support may include guidance and advising, emotional support, tangible assistance, self-disclosure, and support related to management of child problems. Wolfe (1988) has developed a useful outline, entitled the Parent Interview and Assessment Guide, that can be a valuable resource. The Child Abuse and Neglect Interview Schedule, a detailed semistructured interview, is also available (Ammerman, Hersen, \& Van Hasselt, 1988).

It is not uncommon for people within a family to view the same child or set of problems quite differently. Therefore, it is ideal if all caregivers are interviewed, even if only one has been identified as "the client," or if only one will be participating in treatment. Furthermore, there are few data on the actual correspondence between parental report and actions. Maltreating parents may underreport the frequency of their own negative responses or inappropriate behaviors. As mentioned earlier, their reports regarding the 
level of their child's misbehavior may not match the reports of others, nor match actual rates of misbehavior, thus highlighting the need for interviewing multiple informants.

\section{Self -Report Measures}

Several well-validated self-report measures are available that target a wide range of potentially important factors. fu many cases, the paper-and-pencil measures can be given to the client to complete at home, thereby allowing the clinician to spend more actual assessment time in interview or direct observation of parent-child interaction. Clearly, it is not necessary to include all of the measures here in a comprehensive battery. Those devices that best match the referral concerns and client needs are needed.

Commonly used measures available for assessing general psychological functioning are the Minnesota Multiphasic Personality Inventory-2 (MMPI-2; Butcher, Dahlstrom, Graham, Tellegen, \& Kaemmer, 1989) or the Symptom-Checklist-90-Revised (SCL-90-R; Derogatis, 1983). The validity scales of the MMPI-2 are valuable for screening for deviant test-taking attitudes (e.g., attempts to present oneself in an overly positive fashion). The SCL-90-R is particularly useful in that it is brief, yet covers a variety of symptoms (global indices of functioning as well as Somatization, Obsessive-Compulsive, Interpersonal Sensitivity, Depression, Anxiety, Hostility, Phobic Anxiety, Paranoid Ideation, Psychoticism).

Specific assessment of parental knowledge about and expectations of child development is more complicated, as normative levels and timing of developmental milestones are relatively variable. The Parent Opinion Questionnaire (Azar \& Rohrbeck, 1986) is useful to assess the appropriateness of a range of child behaviors. A total score is obtained and six subscales are scored: Self-Care, Family Responsibility and Care of Siblings, Help and Affection to Parents, Leaving Children Alone, Proper Behavior and Feelings, and Punishment. A second device, useful when older children are involved, is the Family Beliefs Inventory (Roehling \& Robin, 1986), which provides a measure of adherence to unreasonable beliefs particular to parent-adolescent conflict situations. On the parent side, the beliefs measured include ruination, perfectionism, approval, obedience, self-blame, and malicious intent. On the adolescent side, the beliefs are ruination, unfairness, autonomy, and approval.

Many devices are available to assess child behavior problems and child-management and parent-child interaction skills. The informants for the devices can be parents, teachers, or other adults familiar with the child. Two of the most commonly used devices are the Child Behavior Checklist (CBCL; Achenbach, 1991) and the Eyberg Child Behavior Inventory (ECBI; Eyberg \& Ross, 1978). The CBCL consists of two main scales: Social Competence and Behavior Problems. The Social Competence scales include Activities, Social, and School subscales. The Behavior Problems scale is composed of 118 items. The actual subscales vary according to the gender and age of the child, but may include Anxious, Depressed, Uncommunicative, Obsessive-Compulsive, Somatic Complaints, Social Withdrawal, Ineffective, Aggressive, and Delinquent. The ECBI is shorter than the CBCL and can be used more easily as a repeated measure to assess behavior change during and after treatment. The ECBI is composed of 36 behavior problems that are rated on a 7-point scale for frequency. Respondents are also asked to indicate which behaviors they consider a problem.

Knowledge about behavioral principles as they apply to child management is an area of particular relevance to skills-based interventions for maltreatment. A measure de- 
signed to assess parental knowledge about child management is the Knowledge of Behavioral Principles as Applied to Children, which is composed of 50 multiple-choice items (KBPAC; O'Dell, Tarler-Benlolo, \& Flynn, 1979). Although the KBPAC can be a useful clinical tool, the length and relatively advanced reading level may make it difficult for many maltreating parents to complete independently (Hansen et al., 1998).

Stress can arise from many different sources, some of which may be particular to the role of parenting (e.g., child misbehavior) and some of which may not (e.g., poor physical health). General measures of stress may be valuable to identify the impact of recent stressful experiences of maltreating parents. The Life Experiences Survey (Sarason, Johnson, \& Siegel, 1978) assesses the occurrence and impact of major life events and the Hassles Scale (Kanner, Coyne, Schaefer, \& Lazarus, 1981) assesses occurrence of more minor, commonly occurring stressors. Both of these measures provide data on stressors outside the parent-child relationship that can impact the quality of parenting. The Parenting Stress Index (PSI; Abidin, 1986) was developed for evaluating stress associated specifically with parenting and the parent-child relationship. The PSI is composed of two domains. The Child Domain has scales of Adaptability, Acceptability, Demandingness, Mood Distractibility / Hyperactivity, and Reinforces Parent. The Parent Domain scales include Parent Health, Depression, Attachment, Restrictions of Role, Sense of Competence, Social Isolation, and Relationship with Spouse. There is an optional Life Stress scale.

Often parents must cope with stressors, solve problems, and manage anger simultaneously. The Parental Problem-Solving Measure (PPSM; Hansen et al., 1989; Hansen et al., 1995) measures problem-solving skills for child-related and non-child-related areas. Problem situations for the PPSM are classified into one of five problem areas: (a) child behavior and child management, (b) anger and stress control' (c) finances, (d) child care resources, and (e) interpersonal problems. Responses are rated for the number of solutions generated and the effectiveness of the chosen solution. Other self-report problem-solving measures that have shown promise with other populations may also be helpful. For example, the Social Problem-solving Inventory (D'Zurilla \& Nezu, 1988) is a measure of multiple components of problem-solving ability.

Because parental anger responses may follow or be intensified by child behavior problems, anger specifically related to child behavior should be an assessment priority. The Parental Anger Inventory (PAI; DeRoma \& Hansen, 1994; V. M. MacMillan, Olson, \& Hansen, 1988) was developed to assess anger experienced by maltreating parents in response to child misbehavior and other child-related situations. Parents rate 50 child-related situations (e.g., child refuses to go to bed, child throws food) as problematic or nonproblematic and rate the degree of anger evoked by each situation. Other paper-andpencil measures of adult anger may also be useful, such as the State-Trait Anger Scale (STAS; Spielberger, Jacobs, Russel, \& Crane, 1983) or the Multidimensional Anger Inventory (Siegel, 1986).

Presence of positive relationships and social supports within the community can decrease the risk of maltreatment. Wahler's (1980) Community Interaction Checklist is useful for evaluating the frequency and tone of social contacts. The marital relationship is a potentially powerful source of support as well as problems. The quality of the caregiver's relationship can be assessed using the Dyadic Adjustment Scale (DAS; Spanier, 1976), a brief measure that uses mostly Likert-type rating scales to assess the quality of the relationship. The DAS provides a standard score that corresponds to the degree of dissatis- 
faction in the relationship and the score can be compared with normative data from distressed and nondistressed couples.

Given the likelihood of aggression between adults within the home, the brief Conflict Tactics Scales (CTS; Straus, 1979) or the more thorough Revised Conflict Tactics Scales (CTS2; Straus, Hamby, Boney-McCoy, \& Sugarman, 1996) are valuable for assessing the extent to which partners engage in physical or psychological attacks when in conflict and their use of negotiation or reasoning. The CTS2 has added scales to address sexual coercion and injury. Items assess a wide range of tactics, from items such as "I agreed to try a solution to a disagreement my partner suggested " to "I used a gun or a knife on my partner." Respondents are asked to report on their own and their significant other's behavior.

For the specific assessment of the risk of maltreatment, the Child Abuse Potential Inventory (CAPI; Milner, 1986) can be used. This device provides an Abuse Potential Scale, which is divided into six factor scales: Distress, Rigidity, Unhappiness, Problems with Child and Self, Problems with Family, and Problems with Others. Three validity scales, Lie, Random Response, and Inconsistency, allow for examination of deviant response styles, including Fake-Good, Fake-Bad, and Random Responding. Elevated abuse scores indicate that the respondent exhibits an assortment of personal and interpersonal features that are similar to characteristics found in known child physical abusers (Milner, 1994). As highlighted by the test's author, it is inappropriate to use anyone test, such as the CAPI, as a "diagnostic criterion" (Milner, 1991). Therefore, although the CAPI can identify risk, it is not to be used for the identification or substantiation of actual maltreatment.

\section{Direct Observation}

Direct observations of parent-child interactions and parenting behavior are essential for a complete assessment. Given that physical abuse is composed of discrete episodes of aggression perpetrated by a caretaker, and given that these episodes generally occur in the relative privacy of the home environment, it is unlikely that professionals will actually observe abuse as it occurs. The initial identification of maltreatment is generally made based on the consequences of abuse, rather than direct observation of abusive behavior (Warner \& Hansen, 1994). Direct observation of any behavior can be a time-consuming, costly method of assessment. Yet, direct observation of parent-child interactions, in both the clinic and the home, can yield extremely useful data, which would definitely not be available through other methods (Hansen et al., 1998). Initial observations can serve as baseline data against which behavior change during and after treatment can be evaluated. Videotaping can be an informative, integral part of assessment, especially given the availability and portability of videorecording equipment.

Parent-child interactions can be observed in unstructured play situations, such as the commonly used Child's Game procedure (Forehand \& McMahon, 1981). In this procedure, parents are told to play with their child but to allow the child to structure the activity. The interactions are observed for approximately $10 \mathrm{~min}$, after which the parents ask the child to put away the toys. The Behavioral Coding System (Forehand \& McMahon, 1981 ) is straightforward and particularly useful for observing such parent-child interactions in the context of parent training. The appropriateness of child behavior is recorded, as well as the parental antecedents (command, warning, question, attend, reward), child responses (compliance, noncompliance), and parental consequences (attend, reward). 
More complex observational codes are available for scoring quality and content of parent-child interactions; examples are the Dyadic Parent-Child Interaction Coding System (DPICS; Eyberg \& Robinson, 1981) and the Family Interaction Coding System (Reid, 1978). The DPICS, for example, assesses a variety of positive and negative behaviors. Frequency of 14 parent behaviors (e.g., direct or indirect commands, descriptive or reflective statements, physical positive or negative) and 10 child behaviors (e.g., cry, yell, destructive, compliance, noncompliance) are coded.

Assessment of abusive parents in high-demand child-management situations is particularly important, given the connection between parental discipline efforts and physically abusive behavior (V. M. MacMillan, Olson, \& Hansen, 1991). Parenting skills may be mastered only during low-demand clinic assessments, but not rehearsed in high-arousal situations that are more representative of the parent's natural environment. Because directly observing actual discipline is often difficult, assessments utilizing adult actors (e.g., therapists, research assistants) to present deviant child behavior can be useful. For example, the Home Simulation Assessment (HSA; V. M. MacMillan et al., 1991) measures parent ability to apply child-management skills in realistic problem situations that may occur in the home. Parents are provided with instructions about tasks (e.g., dry the dishes) and asked to do their best at prompting the actors to complete the tasks. "Deviant" scripted behaviors are exhibited by the actors. Parent self-report ratings of stress, anger, and anxiousness are also collected.

Direct observation of the home environment is a necessary component in the assessment of neglect. Lutzker and colleagues developed two very helpful observational rating systems designed to identify and monitor problems in the home. The Checklist for Living Environments to Assess Neglect (CLEAN; Watson-Perczel, Lutzker, Greene, \& McGimpsey, 1988) is a measure of home cleanliness. Item areas in targeted places (e.g., sink, counter) are rated for cleanliness on three dimensions: presence of dirt or organic matter, number of clothes or linens in contact with the item area, and number of nonclothing items or other nonorganic matter in contact with the area.

The actual physical safety of the home environment may be another issue for assessment. The Home Accident Prevention Inventory (HAPI; Tertinger, Greene, \& Lutzker, 1984) was devised to evaluate the safety of home environments of physically abusive and neglectful families. Five categories of potential hazards in the home are evaluated: fire and electrical hazards, suffocation by ingested objects; suffocation by mechanical objects, firearms, and solid and liquid poisons. The type and number of categories under which these hazards are organized can be identified and a summary score of total number of hazardous items can be obtained. In addition to their role in the initial assessment, both the CLEAN and the HAPI can be quite useful throughout treatment to monitor specific changes in the home environment.

\section{Self-Monitoring}

A complete functional analysis of the factors that operate to initiate or maintain abusive interactions often requires asking the parents to record the occurrence of specific behaviors, such as child tantrums or use of current child-management techniques e.g., spanking). It is possible that the very act of having to record the frequency of punitive or aggressive management techniques may decrease the likelihood that parents will use 
them. Of course, as with any self-report measure, it is equally possible that parents may continue to use such techniques, but underreport the frequency with which they do so. Self-monitoring has been useful with maltreatment parents in assessing responses triggered by arousing events (Hansen et al., 1998). Parents can be asked to note a description of each incident that triggered angry feelings, including frustration or tension, and the way in which they dealt with the incident and their feelings (Hansen \& Warner, 1992). Presence and function of potentially positive factors, such as the frequency and quality of social contacts, can also be measured using self-monitoring.

Self-monitoring techniques are particularly adaptable to individualized assessment, as therapists can operationalize a host of different factors or behaviors and devise unique and personalized assessment forms. Alternative arrangements can be provided for clients who have reading or writing difficulties (e.g., tape-recording their data). For example, V. M. MacMillan, Guevremont, and Hansen (1988) developed a self-report measure of stress and anxiety that was completed two to three times a week by a client during audiotaped telephone interviews. Individual items were created based on her own descriptions of her experience in stressful situations (e.g., "light-headed," "headachy") and read to her over the telephone because she was unable to read.

\section{Information from Others Outside the Family}

Information from professionals outside the family is an integral part of a multi-method, multi-informant approach to assessment. Interagency collaboration is important throughout assessment and treatment. Professionals from schools, medical facilities, and social services may all have various types of contact with the families in different settings and provide data not obtainable from other methods. Interviews and monitoring can all be utilized with professionals in the community, both in the initial assessment and in the monitoring of treatment progress. In cases of neglect, for example, teachers may be in the best position to provide daily, independent ratings of children's hygiene or appropriateness of dress (Hansen et al., 1998).

Maltreating families may be involved with the legal system. In such cases, particularly if the family has been court-mandated for assessment or treatment, it is important that the therapist clarify his or her role and the issue of confidentiality (or the possible lack thereof) at the onset of the assessment process. Milner (1991) and Melton and Limber (1989) provide useful discussions of assessment and testimony issues that may arise when the judicial system is involved.

\section{Issues in Clinical Management}

As noted throughout this chapter, maltreating families are well recognized for their heterogeneity and complexity. Typically, maltreatment is only one of a host of difficulties experienced by the family at any given time. Practical problems may arise, such as lack of transportation to clinics, limited financial resources, and lack of motivation for change (Hansen et al., 1998; Lundquist \& Hansen, 1998). The multiproblem nature of these families presents several issues in terms of their clinical management and a hierar- 
chy of needs and target areas must be developed very early in the treatment. Naturally, decisions about what treatments or combinations of treatments to use will depend heavily on the assessment results. Several other pragmatic issues must be addressed, including the selection of (a) the "client" targeted (e.g., parent, child, family unit), (b) the type of intervention (e.g., group versus individual treatment), and (c) the context of treatment (e.g., home versus clinic). Poor adherence to treatment recommendations and coordination of interagency collaboration present additional challenges to clinical management. Finally, the client may not necessarily be a willing participant in treatment and may not agree with the need for professional involvement.

Because of the complexities associated with treatment of maltreating families, careful consideration of treatment adherence, generalization, and social validity are needed. The full involvement of the parent in treatment is essential and three types of treatment adherence are needed: attending sessions regularly, participating in sessions, and completing out-of-session assignments or tasks (Lundquist \& Hansen, 1998). Completion of a specific functional analysis of adherence and nonadherence responses is important. A variety of factors may contribute to nonadherence, including inadequate instructions and rationale, lack of skills or motivation, and competing contingencies that reinforce noncompliance or punish compliance (Lundquist \& Hansen, in press). Professionals report using a wide variety of strategies for increasing adherence with maltreating families, including antecedent prompting strategies (e.g., telephone reminders, providing training in tasks to be implemented) and consequent strategies (e.g., praise and rewards, feedback), though the effectiveness of such strategies has not been demonstrated empirically (Hansen \& Warner, 1992). In addition, addressing contextual factors that may interfere with compliance (e.g., family conflict, financial problems) can be valuable. Coordination with other agencies (e.g., Child Protective Services, schools) is essential to maximize service provision and minimize service overlap or "splintering of allegiances" (Hansen et at., 1998).

Professionals who work with maltreating parents will, at some time, become involved in the legal system. Melton and Limber (1989) provided a good discussion of the issues involved and suggested that practitioners confine their role in the legal process to investigator, evaluator, or therapist. Abusive and neglectful parents who are court-ordered for assessment or treatment present unique issues for treatment. If the family is involved with the legal system, a certain level of severity or chronicity of maltreatment probably existed that prompted legal involvement. Therefore, patterns of behavior and interacting may be more entrenched and resistant to modification than those present in highrisk families. Despite court mandates, some parents remain noncompliant in terms of attending sessions. These parents tend to be younger and more disadvantaged then those who are more compliant (Butler, Radia, \& Magnatta, 1994). Adherence becomes very critical when the courts are involved. Atkinson and Butler (1996), in a study of mothers court-ordered for assessment, found that mothers who are noncompliant were more likely eventually to lose custody of their children.

Generalization is needed across stimuli, responses, and time, and it is important to program actively for it (Stokes \& Osnes, 1989). A number of strategies may be useful for facilitating generalization, including contacting and recruiting natural consequences (e.g., reinforcers within the family), training diversely (e.g., using sufficient stimulus and response exemplars), and incorporating functional mediators (e.g., common salient physi- 
cal and social stimuli as well as self-mediated physical and verbal stimuli) (Stokes \& Osnes, 1989). It is also useful to target contextual factors (e.g., family stressors) that interfere with assessment or treatment (Lundquist \& Hansen, 1998).

Extended home visitation is a critical element of successful programs designed to prevent the occurrence of child maltreatment among high-risk (e.g., single parent, teenage parent, low socioeconomic status) families (H. L. MacMillan, MacMillan, Offord, Griffith, \& MacMillan, 1994). Home visitation may be the best technique to promote treatment adherence in families in which abuse has already occurred (Hansen \& Warner, 1992; Hansen et al., 1998; Wekerle \& Wolfe, 1993). It is not yet known which exact aspect or aspects of a home visit increase compliance.

It is also important to ensure that the goals, procedures, and outcomes of therapy are socially or functionally valid (Lundquist \& Hansen, 1998). This includes consideration of whether the goals are what the family and society wants and whether achieving the goals would lead to real, functional improvements. Establishing the acceptability of the assessment and treatment procedures and satisfaction with the effects of treatment is also important.

One evaluation of the social validity of behaviorally based interventions suggests that physically abusive and neglectful families find the format of individualized behavioral intervention to be useful (Warner, Ujcich, Ellis, Malinosky-Rummell, \& Hansen, 1992). In particular, maltreating parents found practicing new skills with the therapist and receiving written information most useful. In contrast, practicing anew skill with their child was rated as the least useful aspect of treatment. Thus, professionals working with physically abusive and neglectful parents should be aware that not all aspects of behavioral treatment programs will be equally well accepted or adhered to (Kelley, Grace, \& Elliot, 1990).

Treatment adherence, generalization, and social validity are usually considered separate concepts, but it is important to note that there is significant overlap among the concepts. The more socially valid the goals and the procedures, the more likely the client is to participate in treatment; the more likely the client is to participate in treatment, the more likely the effects will generalize and maintain; the more the effects generalize and maintain, the more socially valid and functional the effects (Lundquist \& Hansen, 1998).

\section{Treatment}

The basic goals of treatment should be to terminate ongoing maltreatment and to prevent future occurrences of maltreatment. These goals are addressed by targeting stressors that compromise parenting, increasing knowledge about child development and behavior, and teaching new skills. It is not enough only to target the acquisition of new skills. Parents who are knowledgeable about child development and have adequate parenting skills may still maltreat their children. Factors that impact utilization of skills must also be targeted.

The literature suggests that if a thorough assessment can identify the probable variables that are contributing to maltreatment, then cognitive-behavioral intervention programs can be very effective in treating physically abusive and neglectful families (Azar \& Wolfe, 1989; Kelly, 1983b; Wolfe \& Wekerle, 1993). Competency-based programs are a good fit with abusive and neglectful families in that the programs can be concrete, educational, and problem-focused (Azar \& Wolfe, 1989; Hansen et al., 1998; Wolfe \& Wekerle, 1993). Interven- 
tions can be tailor-made to suit individual family needs and therefore are very face valid and perhaps less threatening, which may enhance family cooperation with treatment.

Intervention can occur at different levels. The parent, the family situation, resources in the community, or some combination may be targeted. At the level of the maltreating parent, Wolfe and Wekerle (1993) suggest five areas of intervention: (a) symptoms of emotional distress, cognitive impairments, and psychological problems that limit coping; (b) emotional arousal and reactivity to child behavior, anger control, and hostility; (c) poor child management (teaching, discipline, and stimulation); (d) inflexible and limited beliefs and expectations regarding child behavior and development; and (e) negative lifestyle habits (drugs, alcohol). Family issues may need to be addressed, including marital discord or domestic violence, chronic poverty, and social isolation. At the community level, contact with support services (e.g., housing, financial advice, church groups, respite day care) can be initiated or facilitated.

Overall, a variety of factors contribute to difficulties in treating these families: (a) the presence of multiple stressors and limited financial, personal, and social resources within the family for coping with stressors; (b) the often coercive nature of the referral and the possibility that participation in services may be involuntary or under duress; (c) the difficulty of observing abusive behavior; and (d) the need for multiple interventions to treat multiple target areas and family members (Azar \& Wolfe, 1989; Hansen et al., 1998; Wolfe, 1988). Description of approaches for specific treatment of the child, beyond intervention for child management or parent-child interactions, is beyond the offender focus of this chapter; reviews of the treatment of child victims of physical abuse and neglect are available (e.g., Hansen et al., 1990; Walker et al., 1988).

\section{Intervention for Parenting and Related Behaviors}

Research with individual parents or small groups of maltreating parents has suggested that parent training may be effective for improving family functioning and reducing the recurrence of maltreatment (e.g., V. M. MacMillan et al., 1991; Wolfe, Edwards, Manion, \& Koverola, 1988). However, the multiplicity of problems characteristic of maltreating families, in combination with the need for individualized and comprehensive intervention has made the evaluation of such treatment procedures very difficult (Hansen et al., 1998; Wolfe \& Wekerle, 1993).

When general parenting skills are targeted, the goals of intervention typically include (a) increasing knowledge of child development; (b) helping parents establish realistic expectations for child behavior; (c) teaching parents to identify, define, and record common classes of behavior; (d) educating parents on the role of the environment (e.g., antecedents, consequences) in eliciting and maintaining problem behaviors or interactions; and (e) teaching parents nonphysical, nonaggressive techniques of interaction, child management, and problem solving (Walker et al., 1988).

Teaching parents about child development and helping them adopt realistic expectations for child behavior can be achieved by discussing these issues in session and providing parents with reading materials to review outside of session. Evaluations of maltreating parents' perceptions of treatment indicates that they consider interventions such as talking with therapists about new skills, practicing skills with a therapist and receiving written materials to be very useful (Hansen et al., 1998). 
At the time of intervention, parents may need information specific to the needs of their own children, but must develop an appreciation that the needs of children change throughout development. Work with parents of infants should stress the developmental tasks of physiological regulation and the formation of attachment relationships. Parents should be encouraged to provide stable routines, and to respond consistently and appropriately to their infant's needs. Parents of toddlers must be aware that children of this age are in the important phase of developing communication and an autonomous self; toddlers have increased independence and will make new and potentially difficult demandsoften in high-profile situations (e.g., tantrums in grocery stores). Interventions with parents of toddlers may focus on adequate supervision, linguistic stimulation, and the provision of clear commands and positive, consistent consequences for compliance and prosocial behavior. The preschool to school-age years are characterized by the development of self-concept and self-esteem. Behavioral control outside the home (e.g., school) is critical. The development of social networks and academic success continue to be important throughout childhood. These issues will need to be incorporated into individualized parenting skills programs.

Parents may benefit from the opportunity to discuss how children learn from ! watching their parents' behavior. Incorporation of examples from their own adult experiences can be useful in educating parents about the environmental influences on behavior. Parents can be taught methods for prompting the occurrence and increasing the frequency of their children's prosocial behavior. Such methods include monitoring behavior, giving clear commands, and applying principles of reinforcement (e.g., sticker charts, setting up token economies).

The manner in which these methods are presented and practiced may vary widely across treatment programs. The therapists can discuss and demonstrate a skill, practice a skill with a parent, supervise a parent practicing the skill with the child, or instruct a parent to use the skill at home and review the progress in subsequent sessions. Ideally, skills training in the use of mild, nonphysical discipline (e.g., time-out, removal of privileges, extinction, natural consequences) for inappropriate behavior (e.g., tantrumming, teasing) should follow training and mastery of the more positive management techniques.

Several parent-training manuals are available. Although some may not be designed specifically for use with maltreating parents, the basic intervention techniques are the same. Barkley's (1987) "Defiant Children" program and Forehand and McMahon's (1981) text are both very useful. Kelly's (1983a) book on the management of everyday child behavior problems is very direct and practical. Adaptation of basic techniques for working specifically with maltreating parents is reviewed by Walker and colleagues (1988) and Hansen and colleagues (1998).

If limited problem-solving skills are identified in the assessment, then problem-solving skills training must be incorporated into the treatment plan (Hansen et al., 1998; v: M. MacMillan, Guevremont, \& Hansen, 1988). Problem-solving training may be an effective intervention for dealing with the multiple and complex problems of maltreating parents (Hansen et al., 1995). Problem-solving assessment and training may provide a framework for approaching the multifaceted difficulties of maltreating parents, including providing a model from which additional interventions or skill-training procedures might be introduced to broaden the parent's repertoire of potential solutions (Hansen et al., 1989). A goal of problem-solving training would be to increase the identification and imple- 
mentation of nonaggressive solutions and to decrease the tendency to use violence as a resolution technique. Problem solving in relation to child behavior management (e.g., selection of management strategy) would be tied directly to the parenting skills discussed earlier. General problem solving beyond child management issues may also be a focus. Treatment may address day-to-day problems such as from budgeting, scheduling appointments (especially important if multiple agencies are involved), planning meals, and organizing the running of a household.

Developing strategies for managing anger-arousing situations may also be a target. Interventions may include relaxation training, self-control and cognitive coping (Azar \& Wolfe, 1989; Walker et al., 1988). As an initial step in anger management, some parents may actually need to learn how to identify cues-physiological, behavioral and cognitive-related to arousal. An increased level of arousal may compromise a parent's ability to focus on and learn new management techniques. Therefore, it may be best to focus first on general strategies (e.g., generation of possible solutions, selection of solution, evaluation of solution) for less arousing issues (e.g., budgeting) before targeting situations that evoke anger or extreme frustration.

Intervening with maltreating families can be complicated even further in the presence of ongoing substance abuse (Bavolek \& Henderson, 1990; Coleman \& Straus, 1983). Substance abuse can compromise a parent's ability to adhere to treatment. Even the most basic adherence to treatment, attending the sessions, can be affected. In such cases, the substance abuse issues must be addressed before other components of treatment can be initiated. If a child's safety is at risk, temporary placement outside the home may be warranted until the substance abuse is brought under control.

Techniques for increasing the availability and utilization of supports will vary widely depending on the family's situation (Walker et al., 1988). Better use of supports in the extended family should be explored. Existing supports in the community may be underutilized. Some families, having once attempted to engage with a community agency and having had a negative experience, may be unwilling to re-engage. The multiproblem nature of maltreating families may have earned them a reputation in the community as " difficult to work with" or "hopeless," and the therapist may need to act as a liaison between agencies if contact or cooperation have broken down.

An exception to the relatively narrow focus of much of the treatment research is Project 12-Ways, a multifaceted behavioral treatment program for abusive and neglectful parents (cf. Lutzker, 1984; Wesch \& Lutzker, 1991). Treatment targets are varied, including child management and parent-child interactions, problem-solving skill, social support, stress reduction, self-control training, assertiveness, and problems of neglect (e.g., home cleanliness, safety). Evaluations have indicated that families receiving Project 12-Ways services showed generally lower recidivism rates and less frequent removal of children from the home than those who had not received such services. The project has been successfully imitated in other programs throughout the country (Hansen et al., 1998).

\section{Additional Interventions for Neglect}

Neglect poses slightly different treatment issues than physical abuse. Compared with physical abuse, which tends to occur as discrete incidents, neglect is often more chronic and tends to be characterized by the lack of certain behaviors (e.g., lack of supervision) 
rather than inappropriate behaviors (e.g., aggression). Virtually any skill involved in running a household, such as planning meals or budgeting finances, caring for children, such as attending to medical needs or facilitating development, can be targeted, operationalized, and shaped during treatment. In this area the need for individualized assessment and ongoing monitoring is perhaps most pressing. There has been surprisingly little attention to the treatment of neglectful families, with the exception of research from Project 12-Ways (e.g., Lutzker, 1984; Tertinger et al., 1984; Watson-Perczel et al., 1988).

Target areas for treatment may include cleanliness (e.g., Watson-Perczel et al., 1988) or home safety (e.g., Tertinger et al., 1984). For instance, home safety data from the HAPI (Tertinger et al., 1984) may be used to Identify and Improve unsafe areas in the home. Parents may need education to provide general knowledge about home safety, such as which household products are poisonous, and assistance in developing realistic expectations for child behavior. Toddlers are very curious about their environment and may not simply "learn" not to put items into electrical sockets because the parents say not to do so. Rather, the parents may need to take additional precautions. It is important to note that economic factors may impact a parent's ability to carry out treatment recommendations. For example, a therapist may recommend that covers be put on all unused electrical sockets, but the parent may not be in a position to purchase the covers.

Stimulation training may be another area of intervention for neglectful families, particularly if a reduced frequency of positive parent-child interactions is observed in the assessment (Ransen \& Warner, 1992; Lutzker, Lutzker, Braunling-McMorrow, \& Eddleman, 1987). Certain components of general parenting skills training (e.g., Child's Game, Forehand \& McMahon, 1981) provide good opportunities to promote positive, nondirective parent-child interaction.

\section{Course and Prognosis}

Research has documented that behaviorally based treatment programs can improve parenting knowledge, attitudes, skills, and behaviors, and result in fewer child injuries and reports to protective agencies (e.g., see Azar \& Wolfe, 1989; Wolfe \& Wekerle, 1993; Walker et al., 1988, for reviews). Despite evidence for the efficacy of behavioral programs in the treatment of perpetrators of child abuse and neglect, several limitations of this approach have been identified. For example, other serious problems, such as substance abuse or severe parental psychopathology, may compromise the efficacy of behavioral treatments (Azar \& Wolfe, 1989). Skills-training interventions require a high degree of adherence, in that parents must practice and implement new skills outside therapeutic sessions; however, the treatment adherence of physically abusive and neglectful families is notoriously poor (Azar \& Wolfe, 1989; Ransen \& Warner, 1994; Lundquist \& Ransen, 1998). Session attendance, for example, is a very basic, though essential, measure of adherence. One treatment program found that maltreating families attended $72 \%$ of sessions scheduled in the home and $62 \%$ of sessions scheduled in the clinic (Ransen et al., 1998; Malinosky-Rummell et al., 1991).

A related issue is that many abusive families are not self-referred for treatment. The majority of reports of possible maltreatment are made by professionals, such as teachers, physicians, police, and social workers (NCCAN, 1988). Parents may not see their be- 
havior as problematic and may not be willing participants in the assessment or treatment process. Court orders for treatment may increase the likelihood that parents may attend a session, but there are few data to suggest that such orders affect a parent's willingness to adopt new attitudes or to practice new skills outside sessions (Hansen \& Warner, 1994). Even in cases where assessment has been ordered by the court, attendance at sessions can be very low. For example, Butler and colleagues (1994) found that $37 \%$ of mothers courtordered for assessments failed to attend at least two thirds of their appointments.

Intervention programs for maltreating parents vary as to whether they report recidivism rates; the length of time following treatment during which recidivism is monitored also varies. Wesch and Lutzker (1991) examined recidivism rates of maltreating parents receiving Project 12-Ways services (i.e., in-home behavioral intervention with multiple possible treatment targets). Recidivism was broadly defined as occurrence of abuse, neglect, or adoption or foster placement, or some combination. Recidivism rates were $56 \%$ prior to treatment, $13 \%$ during treatment, and $31 \%$ posttreatment. Parents who received services from the state protective service agency and other community programs (but not Project 12 -Ways) had recidivism rates of $42 \%$ prior to treatment, $25 \%$ during treatment, and $25 \%$ posttreatment. In another individualized behavioral intervention program, physical abuse was reported in $22.6 \%$ of the families during the course of treatment and neglect was reported in 3.8\% of the families (Hansen et al., 1998). Following treatment completion, $21 \%$ of the cases were later reopened for maltreatment by Child Protective Services and 23\% were re-referred to the intervention program. Other research has reported a recidivism rate of $16.8 \%$ across a 5 -year follow-up period, with the greatest risk occurring within the first 2 years following treatment; neglect was the most common form of recidivism (Jones, 1995).

Overall, the research evidence suggests that treatment may result in changes in parental behavior (e.g., improved child-management skills) and reduce the likelihood of additional maltreatment. However, more treatment outcome research is needed. Research is needed with larger samples, proper randomization procedures, longer follow-up periods, better demonstration of treatment integrity and replicability, and incorporation of more multimethod assessments with psychometrically sound devices (Hansen et al., 1998; Wolfe \& Wekerle, 1993). In addition, more research is needed on the overall effects of treatment on parent-child relationships and child development (i.e., beyond childmanagement skills).

\section{Summary}

In recent decades, professional and societal awareness of the extent and seriousness of child physical abuse and neglect has increased dramatically. During this time much research evidence has accumulated that describes child maltreatment as a multidimensional problem with multiple causes that requires comprehensive, individualized treatment. The multiproblem nature of maltreating families presents a wide variety of assessment and treatment difficulties for clinicians and researchers. Despite the difficulties, we have learned much about the causes, consequences, assessment, and treatment of child physical abuse and neglect in recent years. However, because of the heterogeneity of the problem and the complexities of the research, we still have much to learn. 


\section{References}

Abidin, R. R (1986). Parenting Stress Index (2nd ed.). Charlottesville, VA: Pediatric Psychology Press.

Achenbach, T. M. (1991). Manual for the Child Behavior Checklist/4-18 and 1991 profile. Burlington: University of Vermont.

Ammerman, R. T., Cassisi, J. E., Hersen, M., \& Van Hasselt, v: B. (1986). Consequences of physical abuse and neglect in children. Clinical Psychology Review, 6, 291-310.

Ammerman, R T., Hersen, M., \& Van Hasselt, V. B. (1988). The Child Abuse and Neglect Interview Schedule (CANIS). Unpublished instrument, Western Pennsylvania School for Blind Children, Pittsburgh, PA.

Ammerman, R. T., Hersen, M., Van Hasselt, V. B., Lubetsky, M. I., \& Sieck, W. R. (1994). Maltreatment in psychiatrically hospitalized children and adolescents with developmental disabilities: Prevalence and correlates. Journal of the American Academy of Child and Adolescent Psychiatry, 33, 567-576.

Atkinson, L., \& Butler, S. (1996). Court-ordered assessment: Impact of maternal noncompliance in child maltreatment cases. Child Abuse \& Neglect, 21, 185-190.

Azar, S. T., \& Rohrbeck, C. A. (1986). Child abuse and unrealistic expectations: Further validation of the Parent Opinion Questionnaire. Journal of Consulting and Clinical Psychology, 54, 867-868.

Azar, S. T., \& Wolfe, D. A. (1989). Child abuse and neglect. In E. J. Mash \& R. Barkley (Eds.), Treatment of childhood disorders (pp. 451-489). New York: Guilford.

Azar, S. T., Robinson, D. R., Hekimian, E., \& Twentyman, C. T. (1984). Unrealistic expectations and problem-solving ability in maltreating and comparison mothers. Journal of Consulting and Clinical Psychology, 52, 687-691.

Barkley, R. A. (1987). Defiant Children: A clinician's manual for parent training. New York: Guilford.

Bauer, W. D., \& Twentyman, C. T. (1985). Abusing, neglectful and comparison mothers' responses to childrelated and non-child-related stressors. Journal of Consulting and Clinical Psychology, 53, 335-343.

Bavolek, S. I., \& Henderson, H. L. (1990). Child maltreatment and alcohol abuse: Comparisons and perspectives for treatment. Journal of Chemical Dependency Treatment, 3, 165-184.

Belsky, I., \& Vondra, J. (1989). Lessons from child abuse: The determinants of parenting. In D. Cicchetti \& V. Carlson (Eds.), Child maltreatment theory and research on the causes and consequences of child abuse and neglect (pp. 129-153). New York: Cambridge University Press.

Bousha, D. M., \& Twentyman, C. T. (1984). Mother-child interactional style in abuse, neglect and control groups: Naturalistic observations in the home. Journal of Abnormal Psychology, 93, 106-114.

Butcher, J. N., Dahlstrom, W. G., Graham, J. R., Tellegen, A., \& Kaemmer, B. (1989). Minnesota Multiphasic Personality Inventory-2 (MMPI-2): Manual for administration and scoring. Minneapolis: University of Minnesota Press.

Butler, S. M., Radia, N., \& Magnatta, M. (1994). Maternal compliance to court-ordered assessment in cases of child maltreatment. Child Abuse \& Neglect, 18, 203-211.

Cicchetti, D., \& Lynch, M. (1995). Failures in the expectable environment and their impact on individual development: The case of child maltreatment. In D. Cicchetti \& D. J. Cohen (Eds.), Developmental psychopathology: Vol. 2. Risk, disorder and adaptation (pp. 32-71). New York: Wiley.

Coleman, D. H., \& Straus, M. A. (1983). Alcohol abuse and family violence. In E. Gottheil, K. A. Druley, T. E. Skoloda, \& H. M. Waxman (Eds.), Alcohol, drug abuse and aggression (pp. 104-124). Springfield, MA: Thomas.

Derogatis, L. R. (1983). SCL-90-R: Administration, scoring, and procedures manual-II. Towson, MD: Clinical Psychometric Research.

DeRoma, V. M., \& Hansen, D. J. (1994, November). Development of the Parental Anger Inventory. Paper presented at the meeting of the Association for the Advancement of Behavior Therapy, San Diego, CA.

Dowdney, L., \& Skuse, D. (1993). Parenting provided by adults with mental retardation. Journal of Child Psychology and Psychiatry, 34, 25-47.

D'Zurilla, T. I., \& Nezu, A. M. (1988, November). Development and preliminary evaluation of the Social Problem-Solving Inventory. Paper presented at the convention of the Association for the Advancement of Behavior Therapy, New York.

Eyberg, S. M., \& Robinson, E. A. (1981). Dyadic Parent-Child Interaction coding system: A manual (Manuscript. No. 2582). San Rafael, CA: Social and Behavioral Sciences Documents, Select Press.

Eyberg, S. M., \& Ross, A. W. (1978). Assessment of child behavior problems: The validation of a new inventory. Journal of Clinical Child Psychology, 7, 113-116.

Falshaw, L., Browne, K. D., \& Hollin, C. R (1996). Victim to offender: A review. Aggression and Violent Behavior, 4, 389-404.

Forehand, R., \& McMahon, R (1981). Helping the noncompliant child: A clinician's guide to parent training. New York: Guilford. 
Frodi, A. M., \& Lamb, M. E. (1980). Child abusers' responses to infant smiles and cries. Child Development, 51, 238-241.

Hansen, D. J., \& Warner, J. E. (1992). Child physical abuse and neglect. In R. T. Ammerman \& M. Hersen (Eds.), Assessment of family violence: A clinical and legal sourcebook (pp. 123-147). New York: Wiley.

Hansen, D. J., \& Warner, J. E. (1994). Treatment adherence of maltreating families: A survey of professionals regarding prevalence and enhancement strategies. Journal of Family Violence, 9, 1-19.

Hansen, D. J., Pallotta, G. M., Tishelman, A. C., Conaway, L. P., \& MacMillan, V. M. (1989). Parental problem-solving skills and child behavior problems: A comparison of physically abusive, neglectful, clinic and community families. Journal of Family Violence, 4, 353-368.

Hansen, D. J., Conaway, L. P., \& Christopher, J. s. (1990). Victims of child physical abuse. In R. T. Ammerman \& M. Hersen (Eds.), Treatment of family violence: A sourcebook (pp. 17-49). New York: Wiley.

Hansen, D. J., Pallotta, G. M., Christopher, J. s., Conaway, R. L., \& Lundquist, L. M. (1995). The Parental Problem-Solving Measure: Further evaluation with maltreating and nonmaltreating parents. Journal of Family Violence, 10, 319-336.

Hansen, D. J., Warner-Rogers, J. E., \& Hecht, D. B. (1998). Implementing and evaluating an individualized behavioral intervention program for maltreating families: Clinical and research issues. In J. R. Lutzker (Ed.), Handbook of child abuse research and treatment. (pp. 133-158). New York: Plenum.

Hecht, D. B., Hansen, D. J ., \& Chandler, R. M. (1996, August). Parental anger towards children: Assessment issues in child maltreatment. In L. Peterson (Chair), Beyond parenting skills: Parent-child relationships and child maltreatment. Symposium conducted at the American Psychological Association Convention, Toronto, Ontario, Canada.

Hill, H. M., Hawkins, s. R., Raposo, M., \& Carr, P. (1995). Relationship between multiple exposures to violence and coping strategies among African-American mothers. Violence and Victims, 10, 55-71.

Jones, D. P. H. (1995). The outcome of intervention [Editorial]. Child Abuse \& Neglect, 19, 1363-1377.

Kanner, A. D., Coyne, J., Schaefer, C., \& Lazarus, R. s. (1981). Comparison of two modes of stress measurement: Daily hassles and uplifts versus major events. Journal of Behavioral Medicine, 4, 1-39.

Kaufman, J., \& Zigler, E. (1989). The intergenerational transmission of child abuse. In D. Cicchetti \& V. Carlson (Eds.), Child maltreatment theory and research on the causes and consequences of child abuse and neglect (pp. 129-153). New York: Cambridge University Press.

Kelley, M. L., Grace, N., \& Elliott, s. N. (1990). Acceptability of positive and punitive discipline methods: Comparisons among abusive, potentially abusive, and nonabusive parents. Child Abuse \& Neglect, 14, 219-226.

Kelly, J. A. (1983a). Solving your child's behavior problems. Boston: Little, Brown.

Kelly, J. A. (1983b). Treating child-abusive families: Intervention based on skills-training principles. New York: Plenum.

Kempe, C. H., \& Heifer, R. (1972). Helping the battered child and his family. Philadelphia: Lippincott.

Kempe, C. H., Silverman, F. N., Steele, B. F., Droegemuller, W., \& Silver, H. K. (1962). The battered child syndrome. Journal of the American Medical Association, 191, 17-24.

Kerig, P. K. (1995). Triangles in the family circle: Effects of family structure on marriage, parenting, and child adjustment. Journal of Family Psychology, 9, 28-43.

Lahey, B. B., Conger, R. D., Atkeson, B. M., \& Treiber, F. A. (1984). Parenting behavior and emotional status of physically abusive mothers. Journal of Consulting and Clinical Psychology, 52, 1062-1071.

Lundquist, L. M., \& Hansen, D. J. (1998). Enhancing treatment adherence, social validity, and generalization of parent-training interventions with physically abusive and neglectful families. In J. R. Lutzker (Ed.), Handbook of child abuse research and treatment. (pp. 449-471) New York: Pergamon.

Lutzker, J. R. (1984). Project 12-Ways: Treating child abuse and neglect from an ecobehavioral perspective. In R. F. Dangel \& R. A. Polster (Eds.), Parent training (pp. 260-297). New York: Guilford.

Lutzker, s. Z., Lutzker, J. R., Braunling-McMorrow, D. B., \& Eddleman, J. (1987). Prompting to increase mother-baby stimulation with single mothers. Journal of Child and Adolescent Psychotherapy, 4, 3-12.

Maccoby, E. E., \& Martin, J. A. (1983). Socialization in the context of the family: Parent-child interaction. In E. M. Hetherington (Ed.), Socialization, personality and social development: Vol. 4. Handbook of child psychology (pp. 1-101). New York: Wiley.

MacMillan, H. L., MacMillan, J. H., afford, D. R., Griffith, L., \& MacMillan, A. (1994). Primary prevention of child physical abuse and neglect: A critical review: Part I. Journal of Child Psychology and Psychiatry, 35, 835-856.

MacMillan, V. M., Guevremont, D. C., \& Hansen, D. J. (1988). Problem-solving training with a multiply distressed abusive and neglectful mother: Effects on social insularity, negative affect, and stress. Journal of Family Violence, 3, 313-326.

MacMillan, V. M., Olson, R. L., \& Hansen, D. J. (1988, November). The development of an anger inventory for use with maltreating parents. Paper presented at the meeting of the Association for the Advancement of Behavior Therapy, New York. 
MacMillan, V. M., Olson, R. L., \& Hansen, D. J. (1991). Low and high deviance analogue assessment of parent-training with physically abusive parents. Journal of Family Violence, 6, 279-301.

Malinosky-Rummell, R., \& Hansen, D. J. (1993). Long-term consequences of childhood physical abuse. Psychological Bulletin, 114, 68-79.

Malinosky-Rummell, R, Ellis, J. T., Warner, J. E., Ujcich, K., Carr, RE., \& Hansen, D. J. (1991, November). Individualized behavioral intervention for physically abusive and neglectful families: An evaluation of the Family Interaction Skills Project. Paper presented at the meeting of the Association for the Advancement of Behavior Therapy, New York.

Melton, G. B., \& Limber, S. (1989). Psychologists' involvement in cases of child maltreatment. American Psychologist, 44, 1225-1233.

Milner, J. S. (1986). The Child Abuse Potential Inventory: Manual (2nd ed). Webster, NC: Psytec.

Milner, J. S. (1991). Additional issues in child abuse assessment. American Psychologist, 46, 80-81.

Milner, J. S. (1993). Social information processing and physical child abuse. Clinical Psychology Review, 13, $275-294$.

Milner, J. S. (1994). Assessing physical child abuse risk: The child abuse potential inventory. Clinical Psychology Review, 14, 547-583.

Milner, J. S., \& Chilamkurti, C. (1991). Physical child abuse perpetrator characteristics: A review of the literature. Journal of Interpersonal Violence, 6, 345-366.

Milner, J. S., Robertson, K. R., \& Rogers, D. L. (1990). Childhood history of abuse and adult child abuse potential. Journal of Family Violence, 5, 15-34.

Muller, R. T., Fitzgerald, H. E., Sullivan, L. A., \& Zucker, R. A. (1994). Social support and stress factors in child maltreatment among alcoholic families. Canadian Journal of Behavioural Science, 26, 438-461.

National Center on Child Abuse and Neglect. (1988). Study of national incidence and prevalence of child abuse and neglect: 1986. Washington, DC: U.S. Department of Health and Human Services.

National Center on Child Abuse and Neglect. (1994). Child maltreatment 1992: Reports from the states to the National Center on Child Abuse and Neglect. Washington, DC: U.S. Department of Health and Human Services.

National Center on Child Abuse and Neglect. (1996). Third national incidence study of child abuse and neglect. Washington, DC: U.S. Department of Health and Human Services.

O’Dell, S. L., Tarler-Benlolo, L., \& Flynn, J. M. (1979). An instrument to measure knowledge of behavioral principles as applied to children. Journal of Behavior Therapy and Experimental Psychiatry, 10,29-34.

Oldershaw, L., Walters, G. C., \& Hall, D. K. (1989). A behavioral approach to the classification of different types of physically abusive mothers. Merrill-Palmer Quarterly, 31, 255-279.

Orme, T. C., \& Rimmer, J. (1981). Alcoholism and child abuse: A review. Journal of Studies on Alcoholism, 42, 273-287.

Quamma, J. P., \& Greenberg, M. T. (1994). Children's experience of life stress: The role of family social support and social problem-solving skills as protective factors. Journal of Child Clinical Psychology, 23, 295-305. ,

Reid, J. B. (Ed.). (1978). A social learning approach to family intervention: Vol. 2. Observation in home settings. Eugene, OR: Castalia.

Reid, J. B., Kavanagh, K., \& Baldwin, D. V. (1987). abusive parents' perceptions of child problem behaviors: An example of parental bias. Journal of Abnormal Child Psychology, 15, 457-466.

Roehling, P. V., \& Robin, A. L. (1986). Development and validation of the Family Beliefs Inventory: A measure of unrealistic beliefs among parents and adolescents. Journal of Consulting and Clinical Psychology, 54, 693-697.

Sarason, I. G., Johnson, J. H., \& Siegel, J. M. (1978). Assessing the impact of life change: Development of the Life Experiences Survey. Journal of Consulting and Clinical Psychology, 46, 932-946.

Schilling, R. F., Schinke, S. P., Blythe, B. I., \& Barth, R. P. (1982). Child maltreatment and mentally retarded parents: Is there a relationship? Mental Retardation, 20, 201-209.

Schindler, F., \& Arkowitz, H. (1986). The assessment of mother-child interactions in physically abusive and nonabusive families. Journal of Family Violence, 1, 247-257.

Siegel, J. M. (1986). The Multidimensional Anger Inventory. Journal of Personality and Social Psychology, 51, 191-200.

Spanier, G. B. (1976). Measuring dyadic adjustment: New scales for assessing the quality of marriage and similar dyads. Journal of Marriage and the Family, 38, 15-28.

Spielberger, C. D., Jacobs, G., Russel, S., \& Crane, R. S. (1983). Assessment of anger: The State-Trait Anger Scale. In J. N. Butcher \& C. D. Spielberger (Eds.), Advances in personality assessment (Vol. 2, pp. 159 187). Hillsdale, NJ: Erlbaum. 
Spinetta, J. J., \& Rigler, D. (1972). The child-abusing parent: A psychological review. Psychological Bulletin, 77, 296-304.

Stasiewicz, P. R., \& Lisman, S. A. (1989). Effects of infant cries on alcohol consumption in college males at risk for child abuse. Child Abuse \& Neglect, 13, 463-470.

Steele, B. F., \& Pollack, C. V., (1974). A psychiatric study of parents who abuse infants and small children. In. R. G. Heifer \& C. H. Kempe (Eds.), The battered child, 2nd ed. (pp. 3-21). Chicago: University of Chicago Press.

Stokes, T. F., \& Osnes, P. G. (1989). An operant pursuit of generalization. Behavior Therapy, 20, $337-355$.

Straus, M. A. (1979). Measuring intrafamily conflict and violence: The Conflict Tactics Scales. Journal of Marriage and the Family, 41, 75-88.

Straus, M. A., \& Kantor, G. K. (1994). Corporal punishment of adolescents by parents: A risk factor in the epidemiology of depression, suicide, alcohol abuse, child abuse and wife beating. Adolescence, 29, 543561.

Straus, M. A., Hamby, S. L., Boney-McCoy, S., \& Sugarman, D. B. (1996). The Revised Conflict Tactics Scales (CTS2): Development and preliminary psychometric data. Journal of Family Issues, 17, $283-316$.

Tertinger, D. A., Greene, B. F., \&. Lutzker, J. R. (1984). Home safety: Development and validation of one component of an ecobehavioral treatment for abused and neglected children. Journal of Applied Behavior Analysis, 2, 159-174.

Trickett, P. K., \& Susman, E. J. (1988). Parental perceptions of child-rearing practices in physically abusive and nonabusive families. Developmental Psychology, 22, 115-123.

Vaillant, G. E. (1995). The national history of alcoholism revisited. Cambridge, MA: Harvard University Press.

Wahler, R. (1980). The insular mother: Her problem in parent-child treatment. Journal of Applied Behavior Analysis, 13, 207-219.

Walker, C. E., Bonner, B. L., \& Kaufman, K. L. (1988). The physically and sexually abused child: Evaluation and treatment. New York: Pergamon.

Warner, J. E., \& Hansen, D. J. (1994). Identification and reporting of physical abuse by medical professionals: A review and implications for research. Child Abuse \& Neglect, 18, 11-25.

Warner, J. E., Ujcich, K., Ellis, J. T., Malinosky-Rummell, R, \& Hansen, D. J. (1992, November). Social validity of an individualized behavioral intervention program for physically abusive and neglectful families: Further evaluation of the Family Interaction Skills Project. Paper presented at the conference of the Association for the Advancement of Behavior Therapy, Boston.

Watson-Perczel, M., Lutzker, J. R., Greene, B. F., \& McGimpsey, B. J. (1988). Assessment and modification of home cleanliness among families adjudicated for child neglect. Behavior Modification, 12, 57-81.

Wekerle, C., \& Wolfe, D. A. (1993). Prevention of child physical abuse and neglect: Promising new directions. Clinical Psychology Review, 13, 501-540.

Wesch, D., \& Lutzker, J. R. (1991). A comprehensive 5-year evaluation of Project 12-Ways: An ecobehavioral program for treating and preventing child abuse and neglect. Journal of Family Violence, 6, 17-35.

Widom, C. S. (1989). Does violence beget violence? A critical examination of the literature. Psychological Bulletin, 106, 3-28.

Wolfe, D. A. (1987). Child abuse: Implications for child development and psychopathology. Newbury Park, CA: Sage.

Wolfe, D. A. (1988). Child abuse and neglect. In E. J. Mash \& L. G. Terdal (Eds.), Behavioral assessment of childhood disorders (2nd ed., pp. 627-669). New York: Guilford.

Wolfe, D. A., \& Wekerle, C. (1993). Treatment strategies for child physical abuse and neglect: A critical progress report. Clinical Psychology Review, 13, 473-500.

Wolfe, D. A., Fairbank, J. A., Kelly, J. A., \& Bradlyn, A. S. (1983). Child abusive parents' physiological responses to stressful and nonstressful behavior in children. Behavioral Assessment, 5, 363-371.

Wolfe, D. A., Edwards, B. E., Manion, I., \& Koverola, C. (1988). Early intervention for parents at risk for child abuse and neglect: A preliminary investigation. Journal of Consulting and Clinical Psychology, 56, 40-47.

Zigler, E., \& Hall, N. W. (1989). Physical child abuse in America: Past, present and future. In D. Cicchetti \& V. Carlson. Child maltreatment: Theory and research on the causes and consequences of child abuse and neglect (pp. 38-75). New York: Cambridge University Press. 